\title{
ERRATA
}

\section{Isolation and Characterization of PKC-L, A New Member of the Protein Kinase C-Related Gene Family Specifically Expressed in Lung, Skin, and Heart}

NINA BACHER, YAFFA ZISMAN, EVA BERENT, AND ETTA LIVNEH

Department of Chemical Immunology, The Weizmann Institute of Science, Rehovot 76100, Israel

Volume 11, no. 1, p. 129: The DNA sequence and deduced amino acid sequence shown in Fig. 1B contain errors in positions 995 to 1100 . The correct sequence is as shown below.

ATATGTAAAATGAATGTGCATATTCGATGTCAAGCGAACGTGGCCCCTAACTGTGGGGTAAATGCGGTGGAACTTGCCAAGACCCTGGCAGGGATG

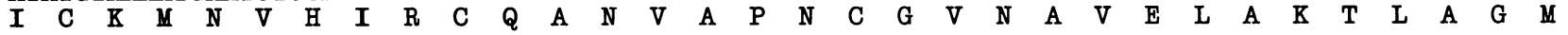

Page 127, column 1, line 2 from bottom: “XhoI DNA linkers" should read "SalI DNA linkers."

\section{Sequences Regulating Temporal Poly(A) Site Switching in the Adenovirus Major Late Transcription Unit}

JAMES D. DEZAZZO, ERIK FALCK-PEDERSEN, AND MICHAEL J. IMPERIALE

Department of Microbiology and Immunology, University of Michigan Medical School, Ann Arbor, Michigan 48109-0620, W. R. Hearst Department of Microbiology, Cornell University Medical College, New York, New York 10028

Volume 11, no. 12, p. 5984, reference 7a: "DeZasso" should read "DeZazzo."

tpr-met Oncogene Product Induces Maturation-Promoting Factor Activation in Xenopus Oocytes

IRA O. DAAR, GRETCHEN A. WHITE, SUSAN M. SCHUH, DOUGLAS K. FERRIS, AND GEORGE F. VANDE WOUDE

ABL-Basic Research Program, P.O. Box B, and Biological Carcinogenesis and Development Program, PRI/Dyn Corp Inc., NCI-Frederick Cancer Research \& Development Center, Frederick, Maryland 21702, and Department of Biochemistry, Howard Hughes Medical Institute and Washington University School of Medicine, St. Louis, Missouri 63110

Vol. 11, no. 12, p. 5985: The article title should read as given above. 